\title{
Cometary and Meteorite Swarm Impact on Planetary Surfaces
}

\author{
JOHN D. O'KeEFE AND ThOMAS J. AHRENS \\ Seismological Laboratory, Division of Geological and Planetary Sciences \\ California Institute of Technology. Pasadena, California 91125
}

\begin{abstract}
The velocity flow fields, energy partitioning, and ejecta distributions resulting from impact of porous (fragmented) icy cometary nuclei with silicate planetary surfaces at speeds from 5 to $45 \mathrm{~km} / \mathrm{s}$ are different than those resulting from the impact of solid ice or silicate meteorites. The impact of $1 \mathrm{~g} / \mathrm{cm}^{3}$ ice spheres onto an atmosphereless anorthosite planetary surface induces cratering flows that appear similar to those induced by normal density anorthosite meteorite impact. Both of these impactors lead to deep transient crater cavities for final crater diameters less than -1 to $\sim 10 \mathrm{~km}$ and for escape velocities $\leq 10^{5} \mathrm{~cm} / \mathrm{s}$. Moreover the fraction of internal energy partitioned into the planetary surface at the cratering site is 0.6 for both ice and anorthosite impactors at $15 \mathrm{~km} / \mathrm{s}$. As the assumed density of the hypothetical cometary nucleus or fragment cloud from a nucleus decreases to $0.01 \mathrm{~g} / \mathrm{cm}^{3}$, the fraction of the impact energy partitioned into planetary surface internal energy decreases to less than 0.01 , and the flow field displays a toroidal behavior in which the apparent source of the flow appears to emanate from a disc or ringlike region rather than from a single point, as in the explosive cratering case. The edges of the crater region are in several cases depressed and flow downward, whereas the center of the crater region is uplifted. Moreover, the resultant postimpact particle velocity llow in some cases indicates the formation of concentric ridges, a central peak, and a distinct absence of a deep transient cavity. In contrast, transient cavities are a ubiquitous feature of nearly all previous hypervelocity impact calculations. The calculations of the flow fields for low density $\left(0.01 \mathrm{~g} / \mathrm{cm}^{3}\right)$ impactors exhibited surface interface (comet-planet) instabilities. These are attributed to both the Rayleigh-Taylor and Helmholtz instability conditions, and we believe that these occur in all flows involving volatile low-density $\left(0.01 \mathrm{~g} / \mathrm{cm}^{3}\right)$ projectiles. It is speculated that these hydrodynamic instabilities can give rise to concentric rings in the inner crater region in large-scale impacts on planetary surfaces, although other mechanisms for their production may also act. The ejecta mass loss versus planetary escape velocity was computed, and these results imply that the critical escape velocity, at which as much material is lost as is being accreted from a planet, ranges from 1.2 to $2.75 \mathrm{~km} / \mathrm{s}$ for encounter speeds of 5 to $15 \mathrm{~km} / \mathrm{s}$, with cometary impactors having a density of 0.01 to $1 \mathrm{~g} / \mathrm{cm}^{3}$. These values compare to 0.83 and $1.5 \mathrm{~km} / \mathrm{s}$ for silicate impactors, thereby indicating that it is more difficult for volatiles than silicates to be accreted onto objects with escape velocities similar to the Moon, Mercury, and Mars. For objects with escape velocities in the 0.1 to $1 \mathrm{~km} / \mathrm{s}$ range the accretional efficiency for silicate and various porosity ices are similar, whereas for objects with escape velocities $<0.1 \mathrm{~km} / \mathrm{s}$ the accretional efficiency of icy impactors becomes significantly lower than for silicate impactors.
\end{abstract}

\section{INTRODUCTION}

As our knowledge of planetary surface morphologies has increased to the point where impact cratered terranes have been successively recognized on the Moon [Shoemaker et al., 1970], Mars [McCaulley et al., 1972], Mercury [Murray et al., 1974], Phobos, Deimos [Veverka and Duxbury, 1977], Callisto, Ganymede [Smith et al., 1979], Amalthea [Veverka et al., 1981], and, recently, tentatively on Venus [Campbell et al., 1979; Pettengill et al., 1979] the question has been raised repeatedly of how the initial density of impacting objects affects the resulting crater shape as well as the partitioning of energy. In part the motivation for studying the effects of cometary impact on planetary surfaces has come from the suggestion of Wetherill [1977], who pointed out the possibility that one half of the terrestrial impact craters could have been produced by retrograde comets, and the

\section{Copyright 1982 by the American Geophysical Union}

Paper number 1B1249.

$0148-0227 / 82 / 001$ B-1249\$05.00 repeated suggestions of Roddy and co-workers [Roddy, 1968; Roddy et al., 1980] that large flat-floored craters such as that at Flynn Creek, Tennessee, could have been produced by porous, possibly cometary impactors. Finally, numerous studies have suggested that the largest meteoritical phenomenon yet documented by man, the Tunguska explosion, was possibly induced by the interaction of the earth with a comet [Krinov, 1966; Petrov and Stulov, 1976; Liu, 1978 ]. Although it is likely that some craters on the terrestrial planets are induced by the impact of icy cometary nuclei, it is not clear what the relative role of comets is in producing the observed impact crater population on the earth and other terrestrial planets. Meteoritical element abundance patterns have recently been used to assign different meteorite classes to the projectiles that have produced some 12 large impact craters on the earth [e.g., Palme et al., 1979]. Aside from the active comets, it may be that potential porous impactors exist in the vicinity of the earth in the form of the Apollo asteroids; these may represent devolatized and short-period cometary cores [Wetherill, 1976]. This latter class of objects could provide an appreciable fraction of the impactor flux recorded on the surfaces and the Moon 
in the last 3 Gy of their history [Shoemaker, 1977]. Roddy [1968] has repeatedly suggested that porous and possibly volatile and cometary objects when impacting terrestrial planetary surfaces give rise to a different type of cratering flow than was first computed by Bjork [1961] for the formation of the Barringer, Arizona, crater. Roddy [1977] recognized a similarity of the Flynn Creek and Steinheim craters, to craters produced in wet alluvium by large-surface and aboveground chemical explosions (Prairie Flat and Snowball). Virtually all previous calculations of the impact into geological materials involving iron, anorthosite, aluminum, and, in the present case, solid ice yielded a large transient cavity with primarily radial motions describable in terms of Maxwell's [1977] Z model [O'Keefe and Ahrens, 1979, 1981; Thomsen et al., 1980]. One exception has been the case of a porous water sphere impacting a graphite surface. In this case a broad, shallow crater with a deep but narrow central deformed area, not unlike Flynn Creek and Ries cross sections, was recently calculated [Roddy et al., 1980]. Earlier cratering calculations of the flow induced by the 20 ton TNT Mixed Company explosion [Ullrich et al., 1977] demonstrated that the sudden application of pressure from gaseous detonation products on a relatively weak sedimentary sequence induced toroidal particle velocity ground motions (upward and toward the axis of the crater) that were also measured by in-situ particle velocity gages. This type of motion must logically occur if the observed flat floor and central peak features result from the intrinsic shock-induced cratering flow in contrast with a flow resulting from the gravity-induced collapse of a large transient crater [Melosh and McKinnon, 1978 ].

The objectives of this study were to characterize the cratering flow and infer the morphology of craters that would be produced by the impact of highly porous (possibly fragmented) and/or volatile hypervelocity impactors. We have sought to test the hypothesis that the impact of porous projectiles could produce flat-floored craters with central peaks and multiple rings. These could arise from intrinsic flow field geometry and/or instabilities at the vaporized projectile-solid target interface. Features such as central peaks and multiple rings are ubiquitous on many scales on the cratered surfaces of the solid planets.

Although flat-floored circularly symmetric deformed, but not excavated, craters have been absent in the results of previous calculations in relatively homogeneous target materials [Bjork, 1961; O'Keefe and Ahrens, 1975, 1977a; Bryan et al., 1978], such features have been produced with special target configurations when a weak target layer overlies a strong strata in several decicentimeter scale impact experiments [Quaide and Oberbeck, 1968].

In the present paper we examine the impact-induced deformation from hypothetical cometary objects having initial densities in the 0.01 to $1 \mathrm{~g} / \mathrm{cm}^{3}$ and heats of vaporization of $\sim 2 \mathrm{~kJ} / \mathrm{g}$ (corresponding to water) to $\sim 10^{7} \mathrm{~J} / \mathrm{g}$ range for impacts in the 5 to $45 \mathrm{~km} / \mathrm{s}$ range. The direct effect of an atmosphere is neglected, although the atmosphere may in fact cause a cometary object to break up into a shower or equivalent very porous impactor. In addition to examining the partitioning of impact energy into internal energy of the impacted planet and impacting cometary material we have also calculated the relative efficiency of shock-induced melting and vaporization by comets on planetary surface materials and the mass loss from a given planet for various escape velocities.

\section{ASSUMPTIONS}

The two most controversial features of the present study are the consideration of impact of planets with objects having densities as low as $0.01 \mathrm{~g} / \mathrm{cm}^{3}$ and the lack of explicit consideration of an atmosphere.

The early suggestion by Roddy [1968] did not include the possibility of an extremely low density. However, two recent studies of the reentry physics of the meteor which produced the 1908 Tunguska explosion concluded that if the kinetic energy of infall was converted into a sudden increase in thermal energy [Liu, 1978] or the incoming bolide transferred its kinetic energy to the atmosphere by ablation and radiative heating of a boundary layer of highly compressed air [Petrov and Stulov, 1976], densities as low as $0.01 \mathrm{~g} / \mathrm{cm}^{3}$ are inferred for the incoming object. Notably, no real constraints on the composition of the object have been obtained from Liu's or Petrov and Stulov's analyses. The discovery of presumably extraterrestrial magnetite and/or silicate-bearing spherules in the Tunguska area [Krinov, 1966; Glass, 1969] does not really constrain the nature of the bolide from being other than essentially water with some silicate and/or metallic minerals. For these reasons we have examined both the impact of readily volatile (water) and refractory porous objects having a range of densities.

Constraints on the constitution of cometary nuclei, the most important of which for the present purposes is density, have been discussed by Whipple [1977]. The apparent brightness versus time data, which presumably result from rotation of the cometary nuclei induced by nonradial gas emission upon approach to the sun, provide an estimate of cometary nuclear density. By equating the centripetal acceleration to the gravitational acceleration and assuming constant comet density with depth the critical rotation period $T$, is given by

$$
T,(\text { hours })=3.3 \rho^{-1 / 2}
$$

where $\rho$ is given in $\mathrm{g} / \mathrm{cm}^{3}$. In (1) the cometary nucleus is assumed to be spheroidal and strengthless. More complex cometary nuclear models have been constructed by Brin [1980]. Observed cometary spin periods are in the range of 3 to 10 hours, implying that $\rho$ is from $10^{-1}$ to $10^{\prime \prime} \mathrm{g} / \mathrm{cm}^{3}$, the latter being the more common value. Fragmentation of cometary nuclei is frequently observed when comets come within several astronomical units of the sun. This may be due to the violent escape of volatiles. However, a weak constraint on cometary density may also be obtained from the stability of cometary nuclei with respect to the tidal stresses imposed by the sun upon a close approach at a distance $r$,

$$
r=2.46 R_{\odot}\left(\rho_{\odot} / n\right) 1 \mathrm{H} 3
$$

where $R_{\odot}$ and $\rho_{\diamond}$ are the solar radius and mean solar density. If $\rho_{\odot}=13 \mathrm{~g} / \mathrm{cm}^{3}$, (2) implies that $\rho \geq 10^{-3} \mathrm{~g} / \mathrm{cm}^{3}$. Thus we conclude that although there is much evidence that the density of comets is $\approx 1 \mathrm{~g} / \mathrm{cm}^{\prime}$, the physical constraints which may be imposed do not yet definitively rule out nuclear densities as low as $0.01 \mathrm{~g} / \mathrm{cm}^{3}$; however, such extremely low values may be only characteristic of new comets prior to initial perihelion [Whipple, 1977]. If the tidal interaction with an earth-sized planet is also considered, 
it may be that very porous objects would be disrupted by planetary tidal stresses.

Because cometary atmospheric interactions are important in the case of the earth [Stulov and Petrov, 1975; Liu, 1978], it is useful to estimate the smallest cometary nuclear radius at which atmospheric effects are important. Using the criteria that the mass of the atmosphere intersected by the projectile (cometary nucleus) should be of the order of the projectile mass [Henderson-Sellers et al., 1980], it follows that for normal incidence,

$$
\rho_{1} R_{t} \sim \rho_{0} H
$$

where $\rho_{\text {c }}$ and $R_{1}$ are cometary nuclear density and radius and $\rho_{0}$ and $H$ are the surface density and scale height of the atmosphere. For the earth, $\rho_{0} H=700 \mathrm{~g} / \mathrm{cm}^{2}$. Therefore the critical radius for significant atmospheric interaction will be $<7 \mathrm{~m}\left(10^{6} \mathrm{~kg}\right)$ and $<0.7 \mathrm{~km}\left(10^{10} \mathrm{~kg}\right)$ for cometary objects having densities of 1 and $0.01 \mathrm{~g} / \mathrm{cm}^{3}$, respectively.

Analysis of the criteria for breakup depend, however, in detail on the entry angle $\theta$ (with respect to the horizontal) and the effective strength of the object. No breakup of objects is predicted for atmospheric entry speeds of $30 \mathrm{~km} / \mathrm{s}$, $\theta=30^{\circ}$, and strengths of 50 bars, whereas for objects with $\theta=15^{\circ}$ and strength of 1 bar (more likely for comets) complete breakup is predicted at all entry velocities (up to $72 \mathrm{~km} / \mathrm{s}$ ) for objects having a mass $>10^{7} \mathrm{~kg}$ (radius $\sim 13 \mathrm{~m}$ for ice) [Passey and Melosh, 1980]. This latter situation would result in a cloud of objects according to Passey and Melosh's [1980] calculation and yet would produce a single crater when the impactor was sufficiently large (e.g., $>10^{10} \mathrm{~kg}$, or having a radius $-130 \mathrm{~m}$ for icy objects). The size of the crater which results would presumably depend on the degree of dispersion of fragments. According to Passey and Melosh the Sikhote-Alin bolide was such a fairly weak (10-bar strength) object. Judging from the total number of $\sim 1 \mathrm{~m}$ craters and assuming, these were produced by drastically decelerated objects $(\sim \mathrm{km} / \mathrm{s}$ impact velocity), a total mass of $10^{4} \mathrm{~kg}$ reached the earth's surface. The observed dispersion of craters observed yields a very low value from effective impactor density.

We conclude from this discussion that for large $(>10 \mathrm{~kg}$ ) weak objects entering the earth's atmosphere, atmospheric breakup will result in very low effective impactor densities.

\section{Calculational Method}

In carrying out the present calculation, the pressure $P$, volume $V$, and energy $E$ equation of state representation of the planetary surface was applied in the form of a modified Mie-Gruneisen equation of state of the Tillotson form given by [Tillotson, 1962; Ahrens and O'Keefe, 1977]

$$
P=\left[a+\frac{b}{\left(E /\left(E_{0} \eta^{2}\right)+1\right)}\right] \frac{E}{V}+A \mu+B \mu^{2}
$$

where $\eta=V_{0} / V, \mu=\eta-1$, and $a=0.5$ is the polytropic constant minus 1 , at high temperature. The constant $b$ is defined such that $(a+b)$ is the STP Gruneisen parameter, $\gamma=V(\partial P / \partial E)_{1}$ and $A$ is the bulk modulus. The con-

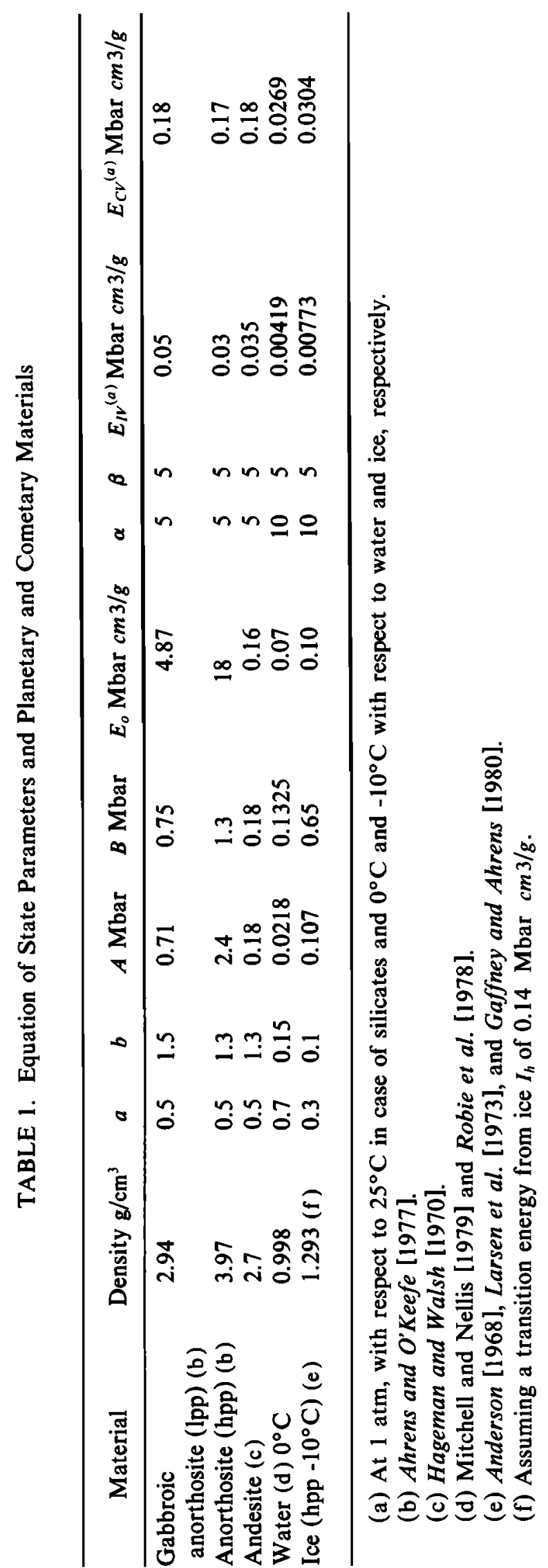




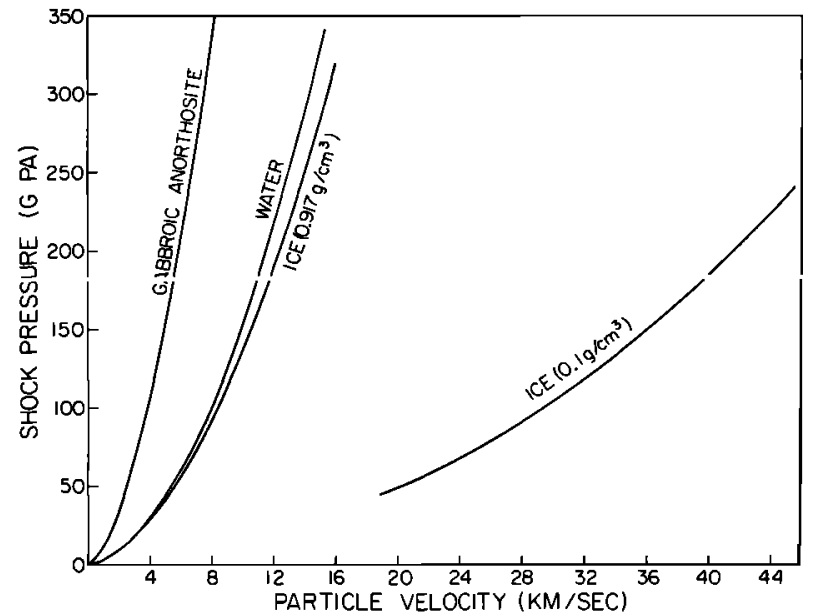

Fig. 1. Pressure-particle velocity Hugoniots for high-pressure region properties of gabbroic anorthosite, water $\left(25^{\circ} \mathrm{C}\right)$, and single-crystal $\left(0.917 \mathrm{~g} / \mathrm{cm}^{3}\right)$ and porous $\left(0.1 \mathrm{~g} / \mathrm{cm}^{3}\right)$ ice at $-10^{\circ} \mathrm{C}$.

stants $b, B$, and $E_{0}$ are obtained by fitting Hugoniot data up to $\sim 1 \mathrm{Mbar}$ and Thomas Fermi calculations in the $10^{2}$ Mbar region. The phase transitions which occur at approx. $0.15 \mathrm{Mbar}$ in silicates or in ice below $0.02 \mathrm{Mbar}$ are taken into account by defining the high-pressure phase regime such that the Rankine-Hugoniot energy is given by

$$
E-P\left(V_{o o}-V\right) / 2-E_{T R}
$$

where $V_{\infty}$ is the specific volume of the starting material or low pressure phase (lpp) and $E_{T R}$ is the increase in internal energy going from the lpp to hpp at STP [Ahrens and O'Keefe, 1977]. For the low pressure phase, $E=0$ at STP.

At high temperatures and low pressures where $V / V_{o o}>1$ for $E>E_{C V}$, where $E_{C V}$ is the energy at standard pressure for complete vaporization, the complete equation of state is given by

$$
\begin{gathered}
P=\frac{a E}{V}+\left\{\frac{b E / V}{\left(E /\left(E_{o} \eta^{2}\right)\right)+1} A \mu \exp \left[\beta\left(1-V / V_{o}\right)\right]\right\} \\
\times \exp \left[-\alpha\left(V / V_{o}-1\right)^{2}\right]
\end{gathered}
$$

where the parameters used in (4) and (6) for gabbroic anorthosite, andesite, water, and ice $I_{h}$ are given in Table 1 . In the partial vaporization regime,

$$
V_{o} / V<1 \quad E_{I V}<E<E_{C V}
$$

where $E_{I V}$ is the energy required to bring a material from normal temperature to incipient vaporization at atmospheric pressure, we use the interpolation relation

$$
P=\frac{\left(E-E_{I V}\right) P_{E}+\left(E_{C V}-E\right) P_{C}}{\left(E_{C V}-E_{I V}\right)}
$$

where $P_{E}$ and $P_{C}$ are the pressure calculated from (6) and (4), respectively.
In carrying out a series of finite difference calculations using the algorithms of Hageman and Walsh [1970] in cylindrically symmetric geometry, icy (water) spherical projectiles, bearing no strength and having initial densities varying from 0.01 to $1 \mathrm{~g} / \mathrm{cm}^{3}$, were assumed to impact planetary surfaces vertically at speeds varying from 5 to $45 \mathrm{~km} / \mathrm{s}$. Although the initial density of these icy projectiles was varied, their initial internal energy density per unit mass was identical. Thus water melting, surface, and crush-up energies were neglected. The actual material constants pertinent for gabbroic anorthosite, water, and ice in the high-pressure regimes [Ahrens and $O^{\prime}$ Keefe, 1977] are given in Table 1 and representative pressure-particle velocities Hugoniots from solutions of (4) and (5) are shown in Figure 1.

All of the present calculations deal with the energetics of the initial partitioning of energy and hence apply to both the large Froude $(F r)$ and Reynolds $(N r)$ regimes:

$$
\begin{aligned}
& \text { Fr }-u^{2} / g l \gg 1 \\
& N r=\rho l u / \mu \gg 1
\end{aligned}
$$

where $u$ and $l$ are the characteristic particle velocity and length scale of the flow, $g$ planetary gravity, $\rho$ density of the flow, and $\mu$ the absolute or dynamic viscosity.

As a result of these conditions, we have used hydrodynamic scaling and discuss partitioning energetics in terms of normalized distance $d$,

$$
d-x / D
$$

where $x$ is actual distance and $D$ is projectile diameter. Normalized time $\tau$ is defined as

$$
\tau \equiv t \quad v / D
$$

where $t$ and $v$ are time and impact velocity, respectively.

Although we have carried out certain of our earlier calculations with finite strength silicate materials [ $O^{\prime} K e e f e$ and

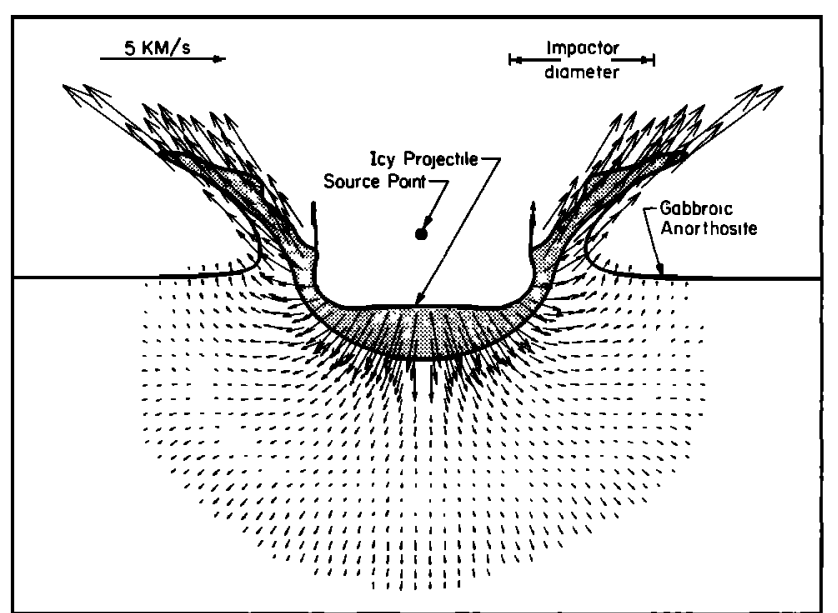

Fig. 2. Particle velocity flow field at $\tau=2.05$ for $1.0 \mathrm{~g} / \mathrm{cm}^{3}$ ice projectile impacting a gabbroic anorthosite surface at $5 \mathrm{~km} / \mathrm{s}$. 
Ahrens, 1977a], we assumed fluidlike rheology for most but not all of the present calculations. Later in this paper, after we describe the initial, inertially controlled flow field, we take these results and apply them in making some generalizations regarding impact ejecta from cometary versus silicate impactors.

We also assumed in some cases that the gabbroic anorthosite rheology was elasto-plastic and possessed a finite strength $Y$, given by

$$
\begin{aligned}
Y(\mathrm{kbar})= & \left(2.7+338 \mu-900 \mu^{2}\right) \\
& \times\left(1-E / E_{m}\right)
\end{aligned}
$$

where $E_{m}$ is the specific internal energy required for melting [O'Keefe and Ahrens, 1977a].

The finite difference grid was constructed with some 154 Eulerian zones to define the projectile and, initially, some 900 zones to define a planetary half space. As the impact induced flows were numerically generated, radial and axial particle velocities, specific internal energy, mass, and the principal stresses in each cell were stored. As the initial computation mesh was consumed by the propagation of shock waves and the ensuing large particle motions associated with cratering flow, the initial grid was enlarged geometrically, approximately 5 times in the course of calculations. In some cases the physical dimension of each zone was increased by a factor of 40 in the course of the calculations. As a result, the computation yields accurate estimates of the amount of planetary surface melted and vaporized and the quantity of high speed ejecta only at early times when the grid spacing is small enough to resolve variation in the entropy density generated by irreversible processes (and hence the mass of melt and/or vapor produced) in various regions of the impacted surface [Ahrens and O'Keefe, 1972, 1977]. The icy projectile is vaporized in virtually all the flows considered. The growth and chemistry of volatiles in planetary regoliths (M. A. Lange and T. J. Ahrens, private communication, 1981) are a problem which has not been addressed in this study.

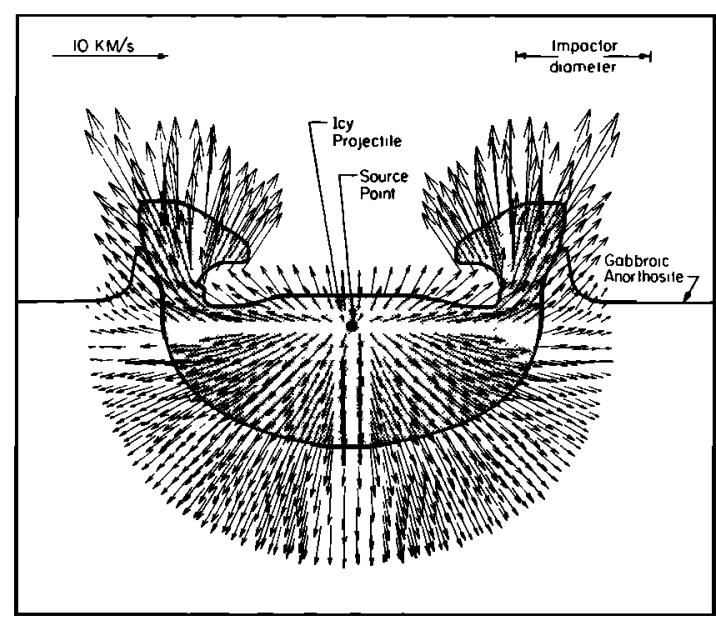

Fig. 3. Particle velocity flow field at $\tau=1.50$ for $1.0 \mathrm{~g} / \mathrm{cm}^{3}$ ice projectile impacting a gabbroic anorthosite surface at $15 \mathrm{~km} / \mathrm{s}$.

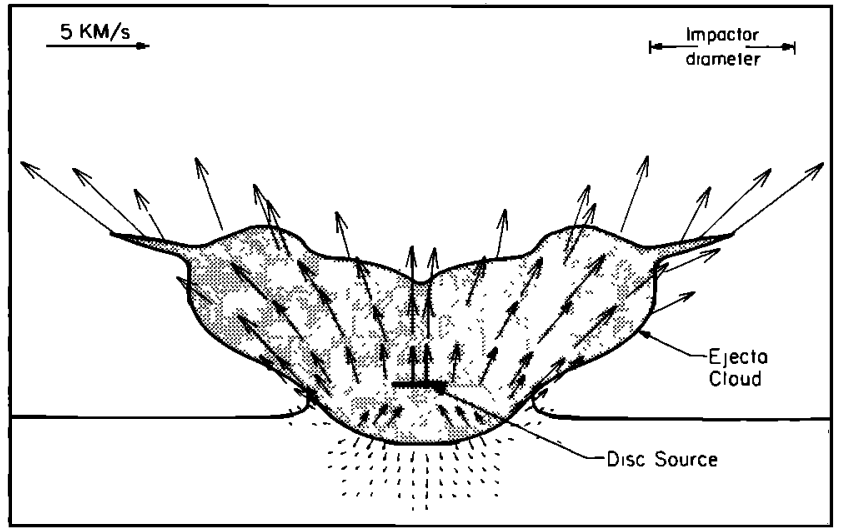

Fig. 4. Particle velocity flow field at $\tau=2.35$ for $0.1 \mathrm{~g} / \mathrm{cm}^{3}$ ice projectile impacting a gabbroic anorthosite surface at $5 \mathrm{~km} / \mathrm{s}$.

\section{COMETARY CRATERING}

The particle velocity field induced at early times as the result of the impact of a $1 \mathrm{~g} / \mathrm{cm}^{3}$ solid ice sphere on a gabbroic anorthosite planetary is shown for impact velocities of 5 and $15 \mathrm{~km} / \mathrm{s}$ in Figures 2 and 3 . The apparent source (indicated) for the flow is slightly above the initial free surface for the $5 \mathrm{~km} / \mathrm{s}$ impact case and slightly below the surface, but within the boundaries of the vaporized ice projectile, for the $15 \mathrm{~km} / \mathrm{s}$ impact case. As in the case of rock impactors, the source point moves downward below the initial free surface with increasing impact velocity [Thomsen et al., 1980], and a bowl-shaped crater is expected. Notably, the subsurface flow is nearly completely radial, and the flow field is similar to that observed at $\tau=0.3$ in the earlier calculations of anorthosite impacting anorthosite by O'Keefe and Ahrens [1977a, Figure $1 c]$ in what they named their cavitation regime.

In the $5 \mathrm{~km} / \mathrm{s}$ impact case, the peak pressure in the flow, 42 kbar, occurs along the center line of the flow in the 'detached shock' region [O'Keefe and Ahrens, 1977a] some two projectile diameters below the original free surface. The icy projectile at low pressure is vaporized but has not yet expanded, although it clearly has the highest particle velocity in the flow. The resulting impact crater flow field is more developed at earlier times for the same impact cratering geometry at $15 \mathrm{~km} / \mathrm{s}$ (Figure 3 ). In this case, the peak pressure of $850 \mathrm{kbar}$ occurs at a depth of 1.8 projectile diameters within the downward driven shock wave, whereas the pressure in the ice projectile is nearly completely relieved below 100 kbar. It appears that the impact of solid ice is similar to that of a solid silicate object. Bowl-shaped craters are expected from the impact-induced flows we have calculated for craters in the diameter range smaller than 1 to 10 $\mathrm{km}$ where gravity effects just begin to appear [O'Keefe and Ahrens, 1978].

The particle velocity field induced at early times for the impact of a porous ice sphere having a density of $0.1 \mathrm{~g} / \mathrm{cm}^{2}$ is shown in Figures 4 and 5 for impact velocities of 5 and 15 $\mathrm{km} / \mathrm{s}$. The flow field geometry has aspects not seen in the case of the impact of dense projectiles. The most obvious is the large plume generated by the vaporization of the porous ice projectile. In addition, the flow field 'source' is not a single point but is shaped like a disc $(5 \mathrm{~km} / \mathrm{s})$ and a ring (15 $\mathrm{km} / \mathrm{s})$. This broadening of the source point results in a shal- 


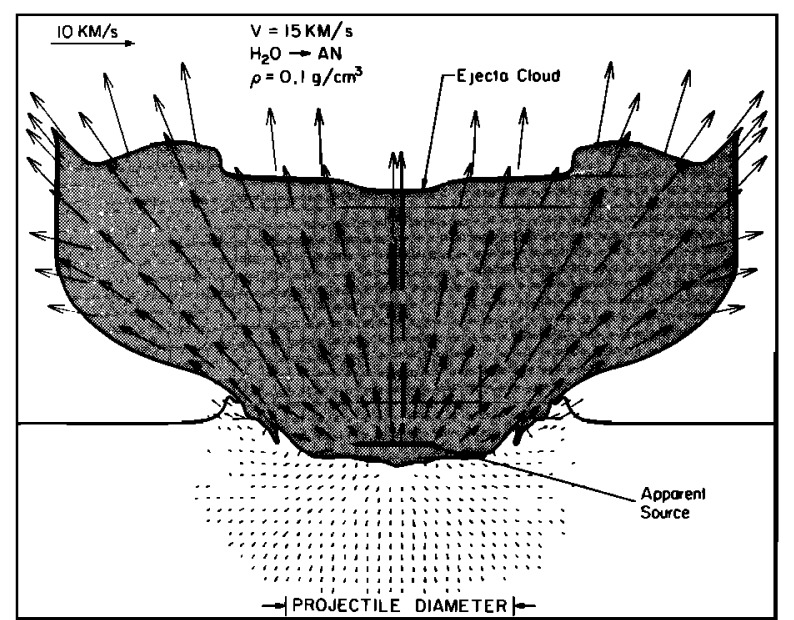

Fig. 5. Particle velocity flow field at $\tau-1.95$ for $0.1 \mathrm{~g} / \mathrm{cm}^{3}$ ice projectile impacting a gabbroic anorthosite surface at $15 \mathrm{~km} / \mathrm{s}$.

lower bowl-shaped crater at relatively early times. The effective source, as in the case of dense impactors, moves downward below the initial free surface with increasing impact velocity (total impact energy).

The particle velocity field changes significantly for the impact of highly porous $\left(0.01 \mathrm{~g} / \mathrm{cm}^{3)}\right.$ ice objects (Figures 6 and 7). The bifurcation of the apparent source of the flow observed for densities of $0.1 \mathrm{~g} / \mathrm{cm}^{3}$ is more apparent for projectile densities of $0.01 \mathrm{~g} / \mathrm{cm}^{3}$ In this case the source has moved below the free surface into the planetary material; this has a profound effect on the geometry of the projectiletarget interface. Toroidal flow fields are produced that could give rise to central peaks. An example of the apparent disc source is indicated in Figure 5. The crater depth to diameter ratios in this regime are in a range of $1: 20$, and according to the trend demonstrated by Schultz et al. [1981] this ratio increases with time. Thus a flat-floored crater with a central peak might be expected.

In order to gain some judgment as to how close to the final crater depth the present calculations can describe the flow, we have examined (Figure 8 ) the crater depth versus normalized time. We conclude that the depths of craters are established between $\tau=10$ and 100 (for $5 \mathrm{~km} / \mathrm{s} \mathrm{impacts).}$ Moreover, the work of Schultz et al. [1981] demonstrates

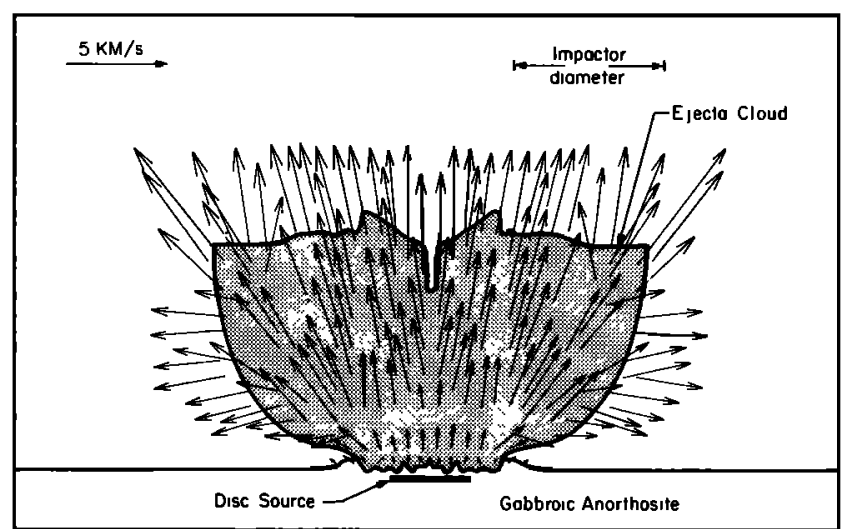

Fig. 6. Particle velocity flow field at $\tau=2.80$ for $0.01 \mathrm{~g} / \mathrm{cm}^{3}$ ice projectile impacting a gabbroic anorthosite surface at $5 \mathrm{~km} / \mathrm{s}$.

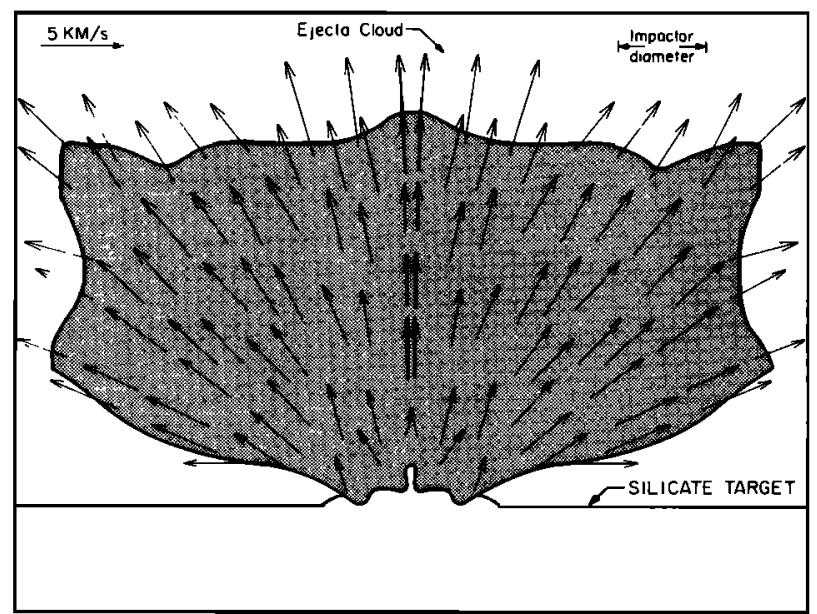

Fig. 7. Particle velocity flow field at $\tau-5.10$ for $0.01 \mathrm{~g} / \mathrm{cm}^{3}$ ice projectile impacting a gabbroic anorthosite surface at $15 \mathrm{~km} / \mathrm{s}$.

that the diameter/depth ratio for impact at $15.8 \mathrm{~km} / \mathrm{s}$ is similar to that at $5 \mathrm{~km} / \mathrm{s}$. We note the depth $\delta$ decreases with porosity and scales approximately as

$$
\delta \propto \rho_{I}^{1 / 2}
$$

where $\rho_{I}$ is the density of the impacting projectile. For projectile densities less than $0.1 \mathrm{~g} / \mathrm{cm}^{3}$, the crater depth is less than the projectile diameter. Moreover, for very low density impactors, the mean of the excavation depth is near zero, and what is shown is the maximum depth of the surface undulations in Figure 8.

The cratering phenomenology exhibited by solid and porous volatile projectiles demonstrates a surprising variety of physical processes. To understand better the source of toroidal flow field and the surface undulations sometimes observed, we computed the cratering due to the impact of porous refractory projectiles. We sought to examine the hypothesis that the interface-instability phenomenology could be associated with vaporization processes. Another motiva-

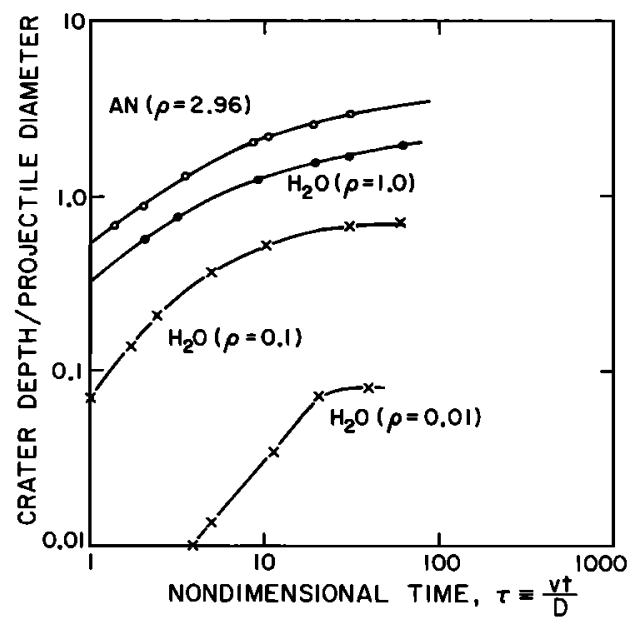

Fig. 8. Normalized crater depth versus nondimensional time for the impact of various density impacts at $5 \mathrm{~km} / \mathrm{s}$ on an anorthositic planetary surface. 


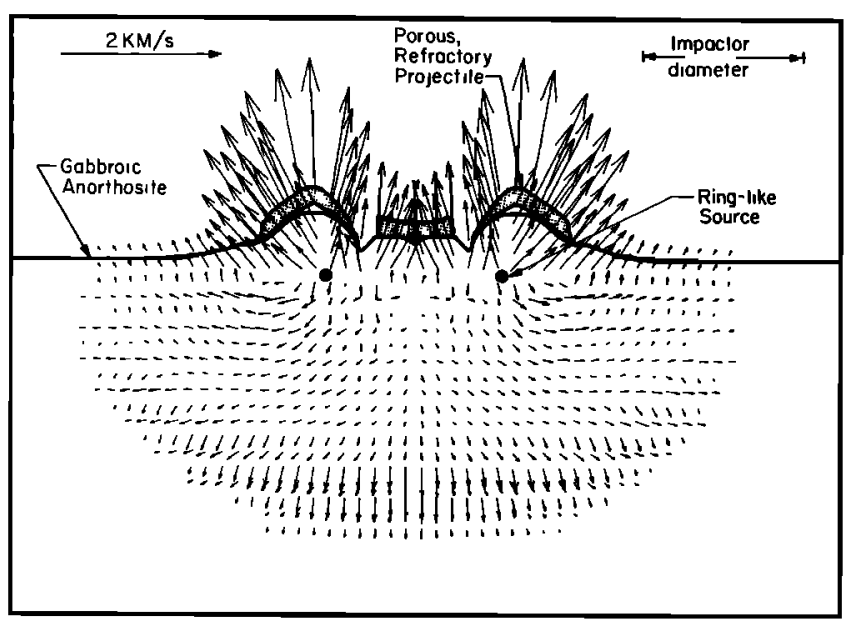

Fig. 9. Particle velocity flow field at $\tau=0.90$ for porous, but refractory $\left(E_{c v}=10^{2} \mathrm{Mbar}-\mathrm{cm}^{3} / \mathrm{g}\right), \quad 0.1 \mathrm{~g} / \mathrm{cm}^{3}$ projectile impacting a gabbroic anorthosite surface at $5 \mathrm{~km} / \mathrm{s}$.

tion for studying such impact flows is the possibility that the impact of porous refractory projectiles might represent the interaction of Apollo objects with terrestrial planetary surfaces. Another model which we might be testing here is that of a disaggregated (fragmented) object or cloud of silicate objects.

The early time particle velocity flow fields for an impact of refractory projectiles having a density of $0.1 \mathrm{~g} / \mathrm{cm}^{3}$ are shown in Figures 9 and 10. The source geometry for the 5 $\mathrm{km} / \mathrm{s}$ case flow is a ring, and the flow geometry is also toroidal. Note the lack of a vapor plume. The ring source is below the initial free surface and within the planetary surface. At an impact velocity of $15 \mathrm{~km} / \mathrm{s}$, the apparent flow source is near the projectile-planetary surface boundary. The depth of the source point does not change much with increasing impact velocity, but the boundary of the projectile-planetary surface boundary moves below the source point.

The particle velocity fields for the impact of highly porous or highly disaggregated refractory (density of $0.01 \mathrm{~g} / \mathrm{cm}^{3}$ ) projectiles has many characteristics of the flow fields of those from impactor densities of $0.1 \mathrm{~g} / \mathrm{cm}^{3}$. Typi-

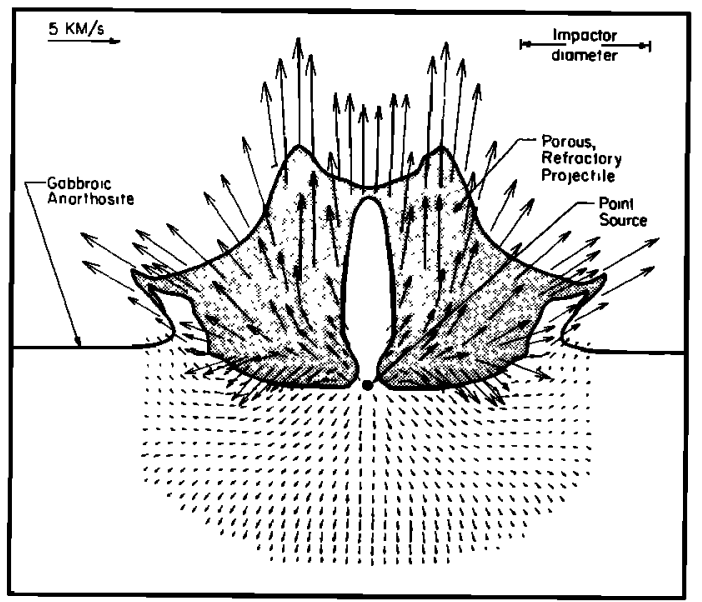

Fig. 10. Particle velocity flow field at $\tau-2.25$ for porous, but refractory $\left(E_{c \nu}=10^{2} \mathrm{Mbar}-\mathrm{cm}^{3} / \mathrm{g}\right), \quad 0.1 \mathrm{~g} / \mathrm{cm}^{3}$ projectile impacting a gabbroic anorthosite surface at $15 \mathrm{~km} / \mathrm{s}$.

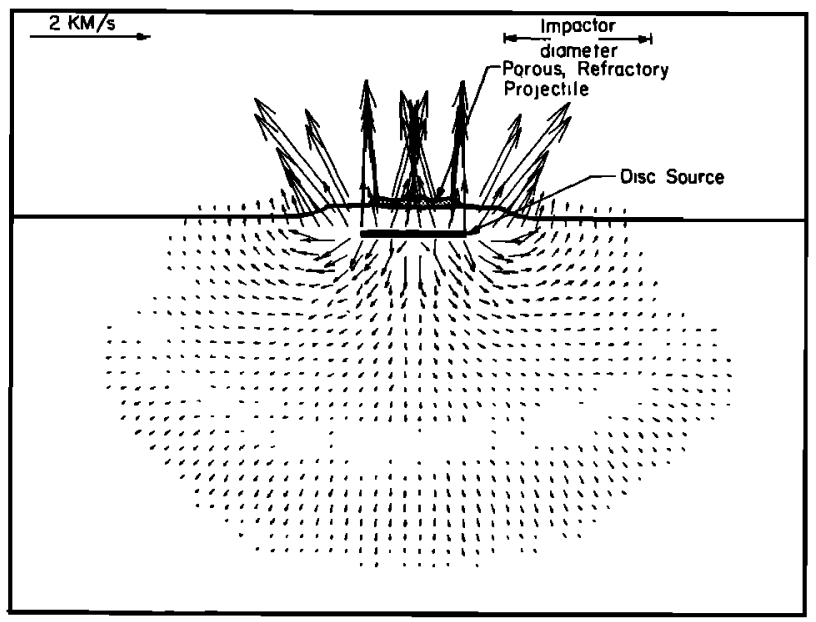

Fig. 11. Particle velocity flow field at $\tau=2.80$ for porous, but refractory $\left(E_{c v}-10^{2} \mathrm{Mbar}-\mathrm{cm}^{3} / \mathrm{g}\right), \quad 0.1 \mathrm{~g} / \mathrm{cm}^{3}$ projectile impacting a gabbroic anorthosite surface at $5 \mathrm{~km} / \mathrm{s}$.

cal flow fields are shown in Figures 11 and 12. The source geometry for the $5 \mathrm{~km} / \mathrm{s}$ is a ring whose position is within the planetary surface, whereas for the $15 \mathrm{~km} / \mathrm{s}$ case the source is in the projectile. Again the trend observed is that with increasing velocity from $5 \mathrm{~km} / \mathrm{s}$ to greater than $15 \mathrm{~km} / \mathrm{s}$ the crater morphology evolves from that with a central mound to a shallow bowl-shaped crater.

The impact of porous volatile objects on solid silicate surfaces gives rise to all the necessary conditions for the classical Kelvin-Helmholtz [Lamb, 1932, p. 374] and RayleighTaylor [Taylor, 1950] surface instabilities.

The condition for the Kelvin-Helmholtz instability is that there is a tangential velocity and density difference,

$$
\left(u_{1}-u_{2}\right)^{2}>\frac{g \lambda}{2 \pi}\left\{\frac{\rho_{1}^{2}-\rho_{2}^{2}}{\rho_{1} \rho_{2}}\right\}
$$

where $u$ is the tangential velocity, $\rho$ the density, $g$ the gravitational acceleration, $\lambda$ the characteristic wavelength of a disturbance, and the subscripts 1 and 2 refer to planetary surface and projectile, respectively. In the case under con-

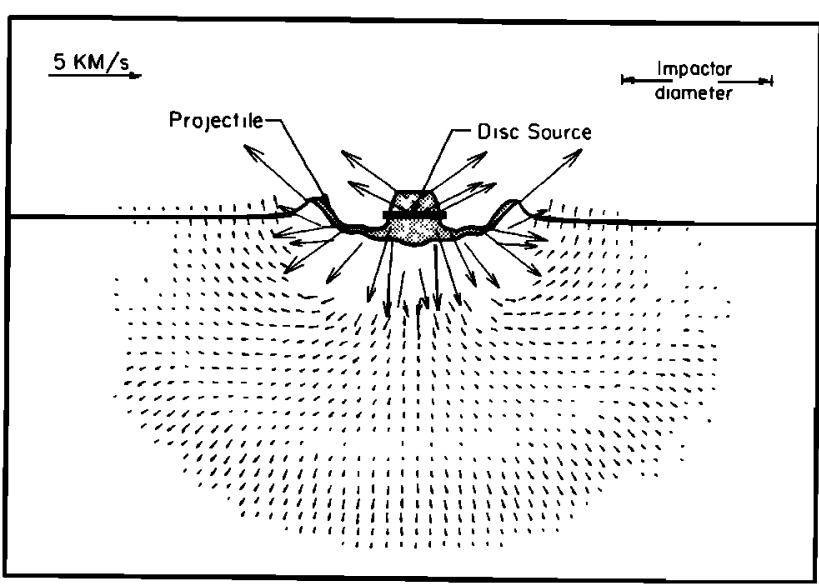

Fig. 12. Particle velocity flow field at $\tau=7.05$ for porous, but refractory $\left(E_{c v}-10^{2} \mathrm{Mbar}-\mathrm{cm}^{3} / \mathrm{g}\right), 0.01 \mathrm{~g} / \mathrm{cm}^{3}$ projectile impacting a gabbroic anorthosite surface at $15 \mathrm{~km} / \mathrm{s}$. 


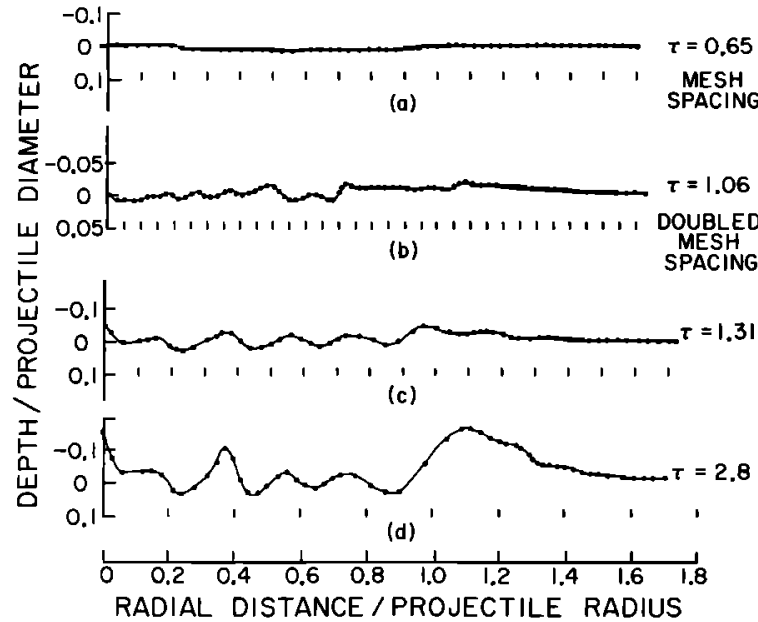

Fig. 13. Configuration of marker particles at interface between the vaporized ice and planet surface for impact of $0.01 \mathrm{~g} / \mathrm{cm}^{3}$ ice projectile onto gabbroic anorthosite at $5 \mathrm{~km} / \mathrm{s}$. Figures $13 a, 13 c$, and $13 d$ are the surface interface at the lime $\tau$ for calculation with the mesh spacing indicated. Shown in Figure $13 b$ is the same case in which the initial computational mesh spacing was decreased by a factor of 2 .

sideration this condition is readily satisfied since there are several orders of magnitude difference in the densities and nearly an order of magnitude difference in tangential velocities. An example of a surface instability that might be attributed to the Kelvin-Helmholtz type is shown in Figure 5.
The instabilities occur near the periphery of the crater lip and may be one source of multiple rings.

The condition of the Rayleigh-Taylor type is also satisfied during the earlier portion of the impact induced flow. If we consider the cometary projectile-planetary surface interface, the impact-induced acceleration of the interface is downward from material 2 (impactor) toward material I (planet). According to the analysis of Taylor [1950], if initial perturbation, amplitude of the interface is $\eta_{0}$, the interface undulation will grow with time $t$ exponentially as

$$
\eta=\eta_{0} \exp \left[\left(\frac{2 \pi a A}{\lambda}\right)^{1 / 2} t\right]
$$

Here $\lambda$ is the wavelength of the initial displacement perturbation, $a$ is the downward acceleration of the interface, and $A$ is the Atwood number,

$$
A=\left(\rho_{1}-\rho_{2}\right) /\left(\rho_{1}+\rho_{2}\right)
$$

Depending on the rheology of the materials, both the dependence of instability velocity and dominant wavelength of the instability can be cast in terms of the characteristic dimensions, viscosity, and/or effective strength of the materials on either side of the interface [e.g., Ramberg, 1967; Barnes et al., 1974; Menikoff et al., 1977, 1978; Drucker, 1980].

Rayleigh-Taylor type instabilities have not been previ-

TABLE 2. Summary of Crater Morphologies for Various Impact Condi-

\begin{tabular}{|c|c|c|c|c|}
\hline \multicolumn{3}{|c|}{ Case } & \multirow[b]{2}{*}{$\begin{array}{l}\text { Expected } \\
\text { Crater Shape } \\
\end{array}$} & \multirow[b]{2}{*}{$\begin{array}{c}\text { Surface } \\
\text { Instabilities }\end{array}$} \\
\hline $\begin{array}{c}\text { Projectile } \\
\text { Density } \mathrm{g} / \mathrm{cm}^{3} \\
\end{array}$ & $\begin{array}{l}\text { Impact } \\
\text { locity kn }\end{array}$ & olatilit & & \\
\hline 1.0 & 5 & high & bowl & no \\
\hline 1.0 & 15 & high & bowl & no \\
\hline 1.0 & 45 & high & bowl & no \\
\hline 0.1 & 5 & high & shallow bowl & no \\
\hline 0.1 & 15 & high & shallow bowl & yes \\
\hline 0.1 & 5 & low & $\begin{array}{l}\text { flat-floored } \\
\text { central peak }\end{array}$ & no \\
\hline 0.1 & 15 & low & $\begin{array}{l}\text { shallow bowl } \\
\text { possible central peak }\end{array}$ & no \\
\hline 0.01 & 5 & high & $\begin{array}{l}\text { flat-floored } \\
\text { central peak }\end{array}$ & yes \\
\hline 0.01 & 15 & high & $\begin{array}{l}\text { flat-floored } \\
\text { central peak }\end{array}$ & yes \\
\hline 0.01 & 45 & high & $\begin{array}{l}\text { flat-floored } \\
\text { central peak }\end{array}$ & yes \\
\hline 0.01 & 5 & low & $\begin{array}{l}\text { flat-floored } \\
\text { central peak }\end{array}$ & no \\
\hline 0.01 & 15 & low & $\begin{array}{l}\text { shallow bowl } \\
\text { possible central peak }\end{array}$ & no \\
\hline
\end{tabular}
tions for Impact into a Silicate Planetary Surface 


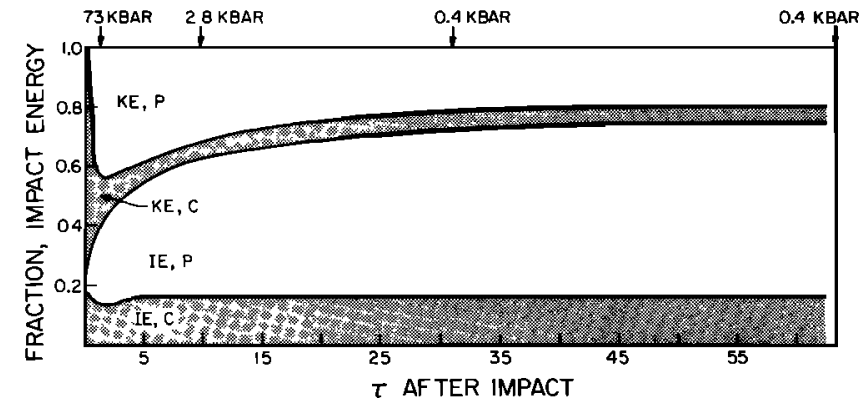

Fig. 14. Energy partitioning versus nondimensionalized time for $1 \mathrm{~g} / \mathrm{cm}^{3}$ icy cometary nucleus impacting gabbroic anorthosite planet at $5 \mathrm{~km} / \mathrm{s}$. IE,C is internal energy of comet; $I E, P$ is internal energy of planet; $K E, C$ is kinetic energy of comet; and $K E, P$ is kinetic energy of planetary surface material. Pressures shown along upper edge of figure indicate the peak pressure in the impactinduced flow at that time.

ously observed and were not calculated to occur in a large number of numerical calculations in which the projectile density was comparable to or greater than the target density (e.g., Figures 3 and 4). However, in the cases of the impact of a volatile low-density projectile, surface instabilities, that might be attributable to a Rayleigh-Taylor type, have been observed and an example is shown in Figure 6.

In order to gain some insight into the question of how the zone spacing of our calculations affects the wavelength and growth characteristics of Rayleigh-Taylor instabilities we have examined (Figure 13) the evolution of the surface between the vaporized ice and planet surface. As can be seen in Figure $13 a$, the planetary surface is slightly depressed $(\tau=0.65)$ when the projectile has penetrated the surface. Subsequently, the expanding water vapor drives surface instabilities at the interface which grow with time. The wavelength of the fastest growing or dominant wavelength is probably a function of the planet viscosity, internal structure and projectile dimensions. The viscosity in the numerical calculations is a function of the mesh spacing. As the mesh spacing decreases, the viscosity increases, and the fastest growing wavelength decreases. A calculation was performed in which the mesh spacing was doubled. This had the effect of decreasing the one of dominant wavelengths in the interface. This is shown in Figure 13b. Because of the mesh spacing dependence on the wavelength, the direct scaling to planetary conditions from the present calculations would be difficult. We conclude from the present work that Rayleigh-
Taylor type instabilities are expected to occur for low-density impactors and that these instabilities are a function of the effective planetary viscosity, structure, and projectile dimension and require further analyses.

The impact of porous volatile projectiles exhibits a variety of crater morphologies not previously described for flows produced by the impact of dense projectile. The range of observed behavior varies from bowl-shaped craters to flatfloored, multiple ringed central peaked craters with features attributable to surface instabilities. The conditions for each of these morphologies depend upon the impact velocity, projectile density, and volatility and are summarized in Table 2. Density is the primarily variable that determines whether or not a bowl-shaped crater will occur. For impactor densities $\geq 0.1 \mathrm{~g} / \mathrm{cm}^{3}$ bowl-shaped craters are formed independent of projectile velocity or volatility. The exception is for lowvelocity impacts $(\sim 5 \mathrm{~km} / \mathrm{s})$ of refractory projectiles where central mounds were observed to occur. For densities $\geq 0.01$, complex crater morphologies are observed early in the flow characterized by flat-floors, multiple rings, and central peaks except for high-velocity $(\geq 15 \mathrm{~km} / \mathrm{s})$ refractory projectiles. In addition to volatility, we examined the effects of material strength and equation of state on crater morphology. The material strength was varied for anorthosite from zero to the values given in (12). This did not change the transition from bowl-shaped to flat-floored craters with decreasing impactor density. The equation of state was changed from that of anorthosite with a high-pressure phase change model (Table 1) to that of andesite (Table 1) with a single phase model; again this also did not change the above generalizations (Table 2).

\section{Energy Partitioning}

The variation of energy partitioning with time and impact velocity for $1 \mathrm{~g} / \mathrm{cm}^{3}$ ice objects impacting a gabbroic anorthosite half-space planet is depicted in Figures 14 and 15. The variation with time of impact energy is qualitatively similar for impacts at speeds varying from 5 to $45 \mathrm{~km} / \mathrm{s}$. Similar energy partitioning is observed for impact onto a finite strength gabbroic anorthosite material (equation (12)) and a material described by the andesite equation of state (Table 1). In all cases, the cometary projectile initially contains all the impactor energy, i.e., $K E, C=1.0$.

Upon shock interaction within one normalized time unit, $\tau=1$, the internal energy of the comet $(I E, C)$ increases

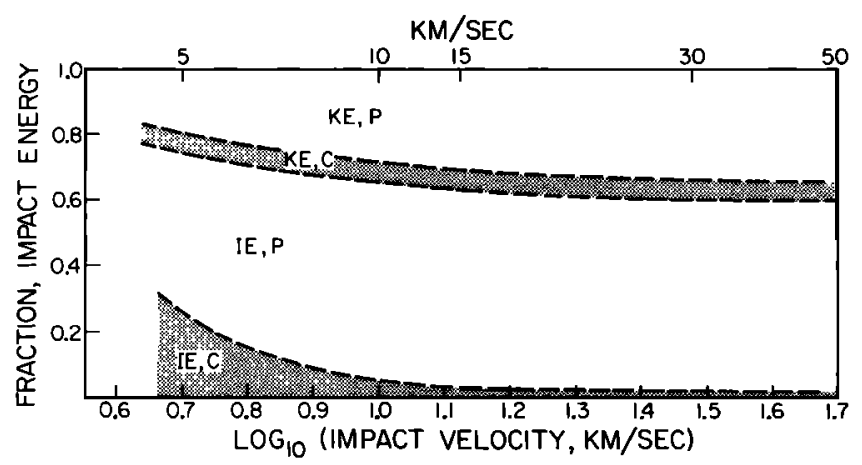

Fig. 15. Final energy partitioning versus impact velocity for $1 \mathrm{~g} / \mathrm{cm}^{3}$ icy cometary nucleus impacting gabbroic anorthosite planet. Notes in caption to Figure 14 apply.

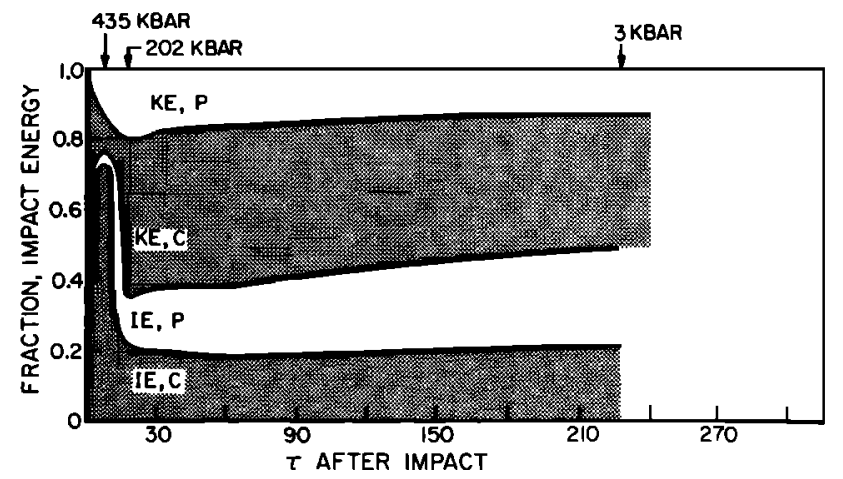

Fig. 16. Energy partitioning versus nondimensionalized time for $0.1 \mathrm{~g} / \mathrm{cm}^{3}$ icy cometary nucleus impacting gabbroic anorthosite planet at $15 \mathrm{~km} / \mathrm{s}$. Notes in caption to Figure 14 apply. 


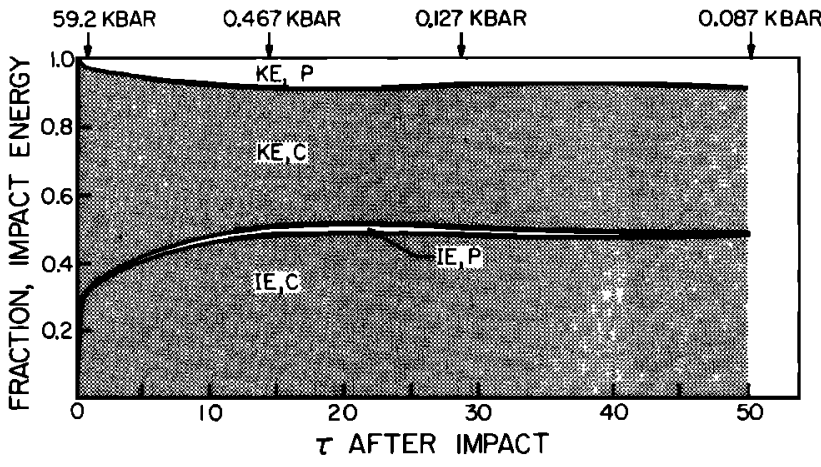

Fig. 17. Energy partitioning versus time for $0.01 \mathrm{~g} / \mathrm{cm}^{3}$ icy cometary nucleus impacting gabbroic anorthosite planet at $5 \mathrm{~km} / \mathrm{s}$. Notes in caption to Figure 14 apply.

sharply. This energy is then, in part, delivered into the kinetic energy of the planetary surface material $(K E, P)$ in immediate contact with it within about two normalized time units. After this interaction the kinetic energy of the comet $(K E, C)$ and $I E, C$ remain nearly constant. The cometary material is effectively detached from the flow, as water vapor escapes the cratering region. During the time that the peak pressure in the subsurface flow decreases from $\sim 10^{2} \mathrm{kbar}$ to nearly zero, the internal energy of the planet $(I E, P)$ steadily increases at the expense of $K E, P$ within the cratered region.

Most of the $K E, P$ is tied-up in the motion of the ejecta, which in turn, on the average is only very lightly shocked, and moves at relatively low velocity in comparison to the initial projectile velocity. Most of this material will impact the planet as secondary ejecta, and thus, eventually, all the energy contained in it will become planetary internal energy except that it will be distributed over a wide area surrounding the impact. Figure 15 demonstrates how, quite surprisingly, low velocity impacts of $1 \mathrm{~g} / \mathrm{cm}^{3}$ ice result in a higher $I E, C$, whereas $K E, C$ represents about $5 \%$ of total energy and is virtually independent of projectile velocity. The internal energy delivered to the planetary material $I E, P$ increases from $-48 \%$ of the total energy at $5 \mathrm{~km} / \mathrm{s}$ to $58 \%$ of the total at $45 \mathrm{~km} / \mathrm{s}$.

As is demonstrated in Figure 16, the peak in projectile internal energy at one normalized time unit becomes very marked with increased velocity for $0.1 \mathrm{~g} / \mathrm{cm}^{3}$ projectiles, whereas this phenomenon was not resolved by the present calculation for $0.01 \mathrm{~g} / \mathrm{cm}^{3}$ projectile impacts depicted in Figures 17 and 18. As is evident from both Figures 17 and

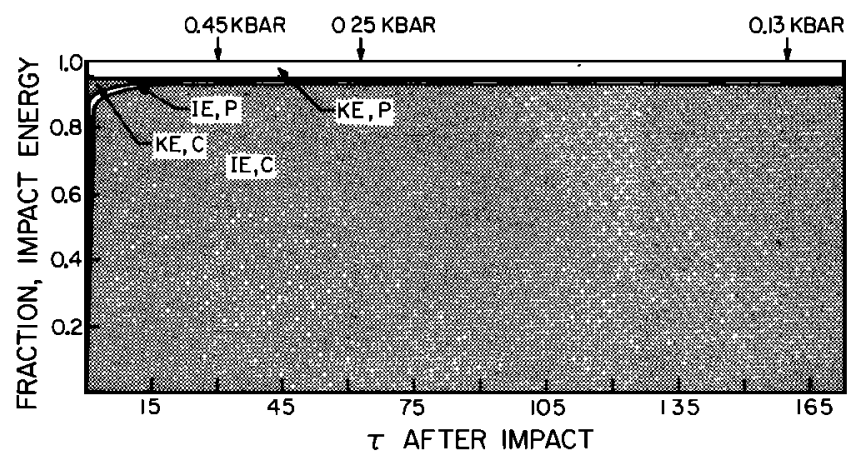

Fig. 18. Energy partitioning versus time for $0.01 \mathrm{~g} / \mathrm{cm}^{3}$ icy cometary nucleus impacting gabbroic anorthosite planet at $15 \mathrm{~km} / \mathrm{s}$. Notes in caption to Figure 14 apply.

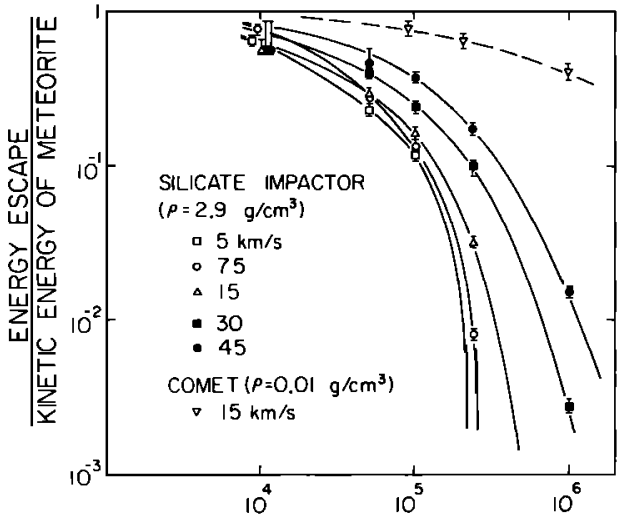

PLANETARY ESCAPE VELOCITY $(\mathrm{cm} / \mathrm{s})$

Fig. 19. Energy escaped in ejecta after impact, normalized by kinetic energy of meteorite, for $2.9 \mathrm{~g} / \mathrm{cm}^{3}$ silicate objects impacting $2 . \dot{9} \mathrm{~g} / \mathrm{cm}^{3}$ silicate planetary surface, versus planetary escape velocity. The relatively large fraction of energy that a $0.01 \mathrm{~g} / \mathrm{cm}^{3}$ icy $15 \mathrm{~km} / \mathrm{s}$ impactor loses upon impact on planetary surfaces with escape velocity $>10^{4} \mathrm{~cm} / \mathrm{s}$ is shown by the upper curve.

18 and the flow fields of Figures 6 and 7, little cometary projectile energy becomes locally coupled into the silicate planetary surface by impact of very porous $\left(0.01 \mathrm{~g} / \mathrm{cm}^{3}\right)$ projectiles. This is dramatically illustrated in Figure 19, which demonstrates that 0.8 of the energy of a $0.01 \mathrm{~g} / \mathrm{cm}^{3}$ water $15 \mathrm{~km} / \mathrm{s}$ impactor escapes a planet that has an escape velocity of $10^{5} \mathrm{~km} / \mathrm{s}$ as compared to only 0.2 for a silicate impactor at the same speed. In the case of a planetary escape velocity of $11 \mathrm{~km} / \mathrm{s}$ (e.g., the earth), $\sim 0.5$ of the energy of the $0.01 \mathrm{~g} / \mathrm{cm}^{3}$ impactor escapes, whereas for a silicate $15 \mathrm{~km} / \mathrm{s}$ impactor, only $\sim 10^{-4}$ of the impact energy is lost to space.

In Figure 20, we compare the energy delivered to a planetary surface via cometary impacts at $15 \mathrm{~km} / \mathrm{s}$ for different initial density comets to that calculated for gabbroic anorthosite and iron projectiles striking a gabbroic anorthosite planet. Clearly, the internal energy deposited into the comet $(I E, C)$ decreases markedly with increasing cometary density. Significantly, the fraction of internal energy retained by the planet for a $1 \mathrm{~g} / \mathrm{cm}^{3}$ comet is about 0.6 ,

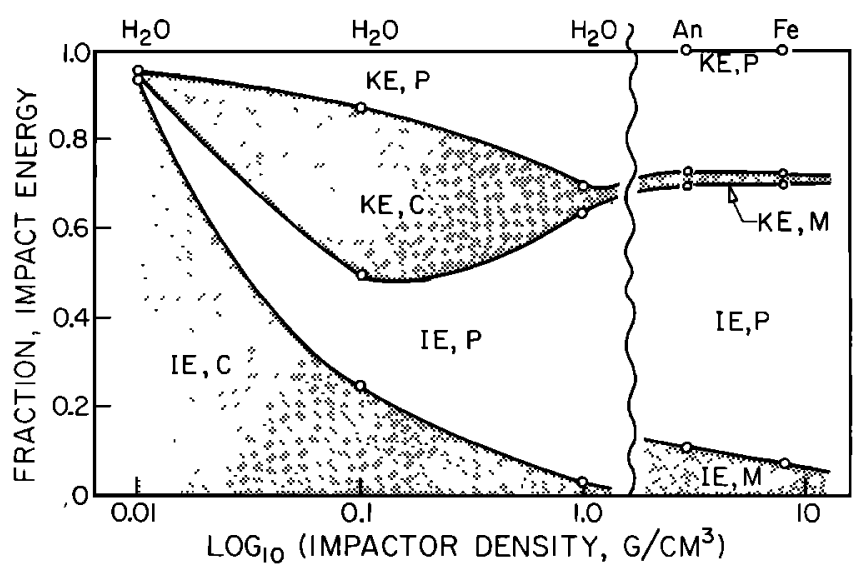

Fig. 20. Energy partitioning versus initial density for $15 \mathrm{~km} / \mathrm{s}$ impacts into a gabbroic anorthosite planet by cometary objects and anorthosite and iron meteorites. (Energy fraction in $I E, P$ is less than from $O^{\prime} K e e f e$ and Ahrens [1977a], since the planetary surface was assumed to be strengthless.) 


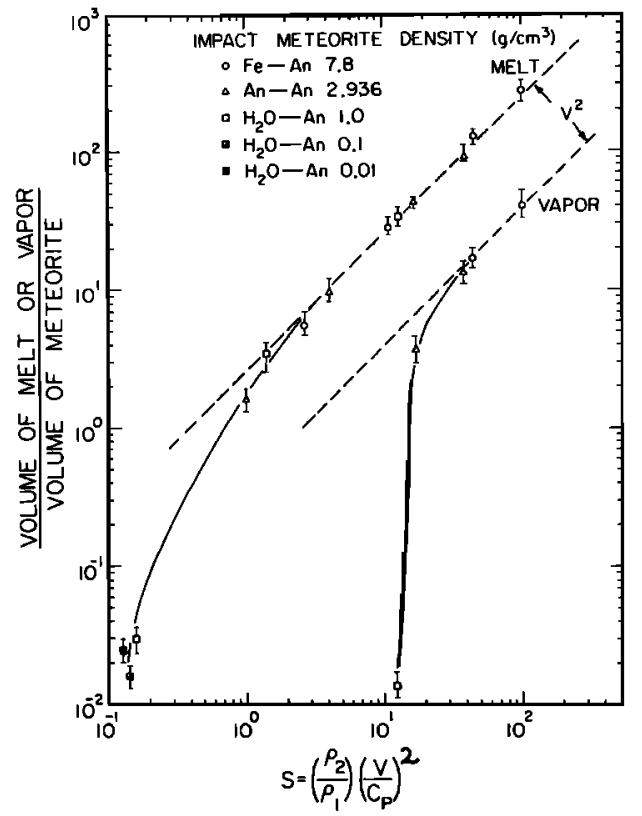

Fig. 21. Volume of melt or vapor (upon cooling to STP) of planetary material normalized by meteorite volume versus similarity parameter, $S-\left(\rho_{2} / \rho_{1}\right)\left(V / C_{P}\right)^{2}$. Here $\rho_{2}$ and $\rho_{1}$, as in equation (16), are the meteorite (projectile) and planetary density, respectively, $V$ is impact velocity and $C_{P}$ is the sound speed of the high-pressure phase of the planetary surface material [e.g., $O^{\prime}$ Keefe and Ahrens, 1977a]. Here An indicates anorthosite, and $\mathrm{Fe}$ and $\mathrm{H}_{2} \mathrm{O}$ have their usual meaning.

slightly less than the 0.6 and 0.7 values appropriate for the anorthosite and the iron meteorite impact case.

On the other hand, the physical reason for the maximum defined for the kinetic energy of the comet $(I E, C)$ at $\sim 0.1 \mathrm{~g} / \mathrm{cm}^{3}$ initial density demonstrated by Figure 20 is not understood. This maximum is, however, based on adequate time dependent results of Figure 16.

The amount of silicate impact melt produced by the impact of icy objects is relatively small as compared to silicate and iron impactors at the same speeds. This is shown in

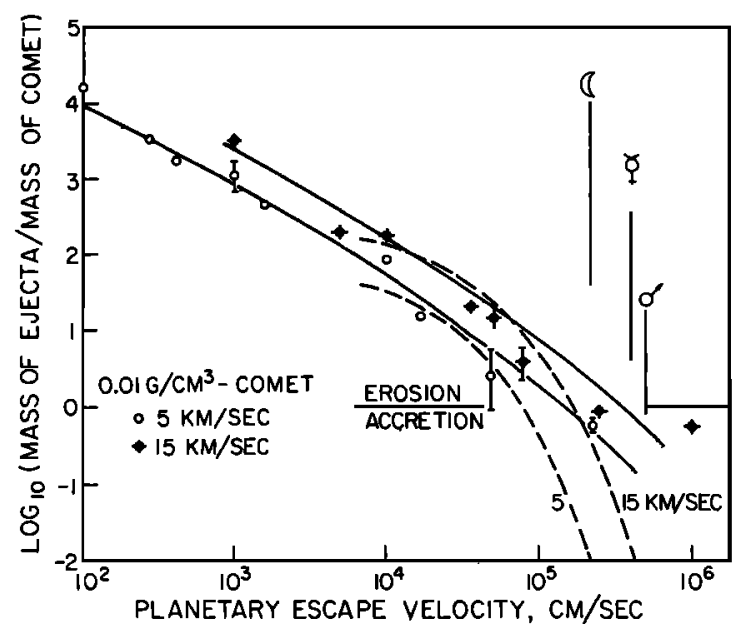

Fig. 22. Logarithm of normalized ejecta mass versus planetary escape velocity for $1 \mathrm{~g} / \mathrm{cm}^{3}$ icy objects impacting anorthosite planetesimals at 5 and $15 \mathrm{~km} / \mathrm{s}$. Dashed curves are results for similar calculations for anorthosite impactors [after $O^{\prime} K e e f e$ and Ahrens, $1977 b]$.

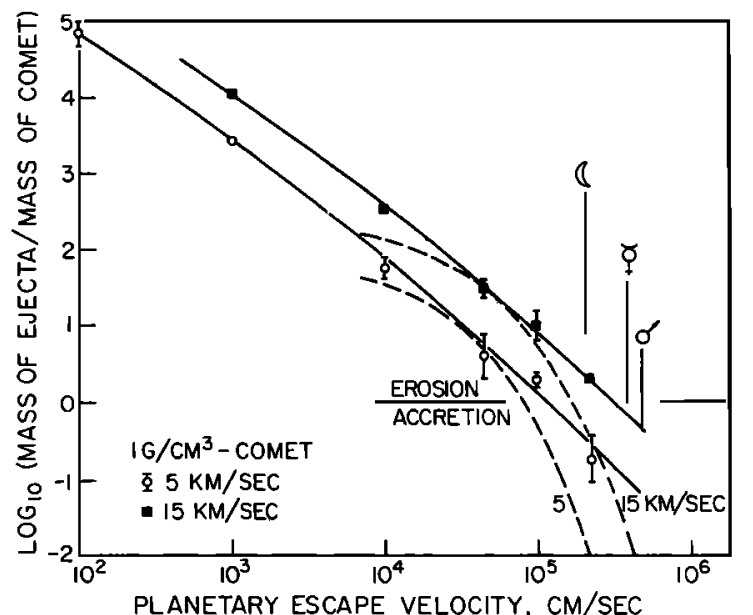

Fig. 23. Logarithm of normalized ejecta mass versus planetary escape velocity for $0.01 \mathrm{~g} / \mathrm{cm}^{3}$ icy objects impacting anorthosite planetesimals at 5 and $15 \mathrm{~km} / \mathrm{s}$. Dashed curves are for anorthosite impactors [after $O^{\prime}$ Keefe and Ahrens, 1977b].

Figure 21 in terms of the similarity variable developed by O'Keefe and Ahrens [1977a]. Notably, $S$ may be considered a normalized stagnation pressure $\rho_{2} V^{2}$, and the representation of Figure 21 may be considered as indicating that stagnation pressures of $\sim 70 \mathrm{GPa}$ (700 kbar) and $100 \mathrm{GPa}(1000$ kbar) are required for the onset of melting and vaporization. At high speeds the melt and vapor production curves are proportional to kinetic energy $V^{2}$.

Finally, we address the question of the efficiency with which planets with silicate surfaces can accrete cometary and presumably volatile objects. A number of authors have suggested [Smith, 1977; Ringwood, 1979; Anders and Owen, 1977] that much of the volatile inventory of the terrestrial planets was accreted late. Thus objects the size of Mercury, the Moon, and, to a lesser degree, Mars were too small to collect hydrocarbons and $\mathrm{H}_{2} \mathrm{O}$ in appreciable quantities at the time that the solar system cooled off to the point that the volatiles would accrete. In Figures 22 and 23 the logarithms of the ratio of the ejecta mass to cometary mass versus planetary escape velocities are plotted for the hypothetical impact of 1.0 and $0.01 \mathrm{~g} / \mathrm{cm}^{3} \mathrm{H}_{2} \mathrm{O}$ bearing comets onto terrestrial surfaces. First, we note that a factor of -2 to -5 more ejecta is produced upon impact of $15 \mathrm{~km} / \mathrm{s}$ than upon impact of $5 \mathrm{~km} / \mathrm{s}$ projectiles. This is true for water impactors having initial densities of 0.01 or $1 \mathrm{~g} / \mathrm{cm}^{3}$. The zero horizontal line has special significance in Figures 22 and 23, since the crossing of the various velocity curves represents the locus of impact and escape velocities for which the ejecta losses to the planet are just equal to the gain or net mass accreted. In the case of $1 \mathrm{~g} / \mathrm{cm}^{3}$ comets this critical escape velocity is 1.2 and $2.5 \mathrm{~km} / \mathrm{s}$ for 5 and $15 \mathrm{~km} / \mathrm{s}$ impactors, respectively. This implies that for planets with escape velocity less than this value, more material is lost than accreted at these encounter speeds. For $0.01 \mathrm{~g} / \mathrm{cm}^{3}$ comets, the critical escape velocities for 5 and $15 \mathrm{~km} / \mathrm{s}$ impactors are 1.4 and $2.75 \mathrm{~km} / \mathrm{s}$, respectively. In both cases for cometary media, the critical escape velocity for parity (no loss, no gain of mass on impact) are at higher escape velocities than the 0.83 and $1.51 \mathrm{~km} / \mathrm{s}$ values previously obtained by $O^{\prime} K e e f e$ and Ahrens [1977b] for anorthosite striking an anorthosite planet at 5 and $15 \mathrm{~km} / \mathrm{s}$, respectively. Therefore for escape velocities of objects in the size range of the Moon, Mercury, and 
Mars, Figures 22 and 23 indicate that these planets accrete anorthosite some $10^{1}$ to $10^{2}$ times more efficiently than they can accrete cometary water at infall velocities of 5 and 15 $\mathrm{km} / \mathrm{s}$. At lower escape velocity in the $10^{4}$ to $10^{5} \mathrm{~km} / \mathrm{s}$ range the anorthosite and cometary ejecta curves coincide, implying that planetesimals composed of rock and ice of widely varying porosity accrete with low, but similar, efficiencies.

Finally, we note that as demonstrated by Figure 19, the impact energy which porous (e.g., $0.01 \mathrm{~g} / \mathrm{cm}^{3}$ ) icy objects can contribute to accreting planets is comparable to that of silicate planetesimals when the growing planet has a low $\left(\sim 10^{-1} \mathrm{~km} / \mathrm{s}\right)$ escape velocity. However, for larger planets with escape velocities of $\sim 10^{\prime \prime} \mathrm{km}$ the impact energy due to volatile impactors retained by the planet declines to $<10 \%$ of that initially delivered by the impactor.

\section{CONCLUSIONS}

There are significant qualitative and quantitative differences in the form of craters produced by porous cometary impactors relative to solid silicate and iron objects on silicate planetary surfaces. The cratering flows induced by both volatile and involatile but porous low-density objects tend to have toroidal streamlines in which the apparent source of the flow is not a point as in an explosion or impact of solid silicate or iron objects but is a ring or disc, which, depending on projectile density or velocity, can be above or below the initial planetary surface. During the cratering flow from porous impactors, the central portions of the craters in many cases have motions upward, whereas the outsides of the craters move downward.

We propose that upon interaction of planetary surfaces with volatile low-density impactors such as cometary nuclei, undulations of the projectile-planet surface can be produced by the mechanisms of the Rayleigh-Taylor and KelvinHelmholtz instabilities. The growth rate of the undulations of the Rayleigh-Taylor instability are determined by the ratio of the difference in density, initial perturbation height and wavelength. The wavelength perturbations are, in turn, presumably controlled by contrast in effective rheology of planetary surface and projectile materials. Kelvin-Helmholtz instabilities form along the transient crater rim on account of the markedly lower density and higher particle velocity of the vaporized projectile versus that of the planetary surface across which the projectile flows. Both instabilities may contribute to concentric rings in the inner region of the craters which are frequently observed on planetary surfaces on many size scales and geological terranes. We recognize, however, that other mecharlisms may produce these features.

The final partitioning of energy from cometary impactors is such that much more of the initial kinetic energy of the projectile resides in the cometary and planetary material ejecta and the internal energy of the cometary material than in the case of impact onto silicate surfaces.

The critical escape velocity at which as much material is ejected from a planet as accreted, for a given impact velocity, is 1.2 to 2.5 and 1.4 and $2.75 \mathrm{~km} / \mathrm{s}$ for 5 to $15 \mathrm{~km} / \mathrm{s}$ cometary impactors having initial densities of 1.0 to $0.01 \mathrm{~g} / \mathrm{cm}$ ' These are considerably higher than the critical accretion escape velocities of 0.83 and $1.5 \mathrm{~km} / \mathrm{s}$ for normal density silicates at similar encounter velocities. This implies that it is more difficult to accrete volatiles for planets which have escape velocities similar to the Moon, Mercury, and Mars than it is to accrete silicate materials. In contrast, in the lower $\left(10^{-1} \mathrm{~cm} / \mathrm{s}\right)$ escape velocity range, the accretional efficiencies for anorthosite and various porosity ices are similar.

Acknowledgments. We appreciate the assistance of J. Peter Watt in constructing an equation of state of water and the contribution of David Jewitl in suggesting bounds on cometary properties and helpful comments during the course of this work and on the final manuscript proferred by David Stevenson. Reviews of the paper by Peter H. Schultz and William B. McKinnon were most helpful. The continued computational assistance of $M$. Lainhart and the support of NASA (NSG 7129) is appreciated. Contribution 3491. Division of Geological and Planetary Sciences, California Institute of Technology, Pasadena, Californıa 91125.

\section{REFERENCES}

Ahrens, T. J., and J. D. O'Keefe, Shock melting and vaporization of lunar rocks and minerals, Moon, 4, 214-249, 1972.

Ahrens, T. J., and J. D. O'Keefe, Equations of state and impactinduced shock-wave attenuation on the moon, in Impact and Explosion Cratering, edited by D. J. Roddy, R. O. Pepin, and R. B. Merrill, pp. 639-656, Pergamon, New York, 1977.

Anders, E., and T. Owen, Mars and the earth: Origin and abundance of volatiles, Science, 198, 453-465, 1977.

Anderson, G. D., The equation of state of ice and composite frozen soil material, Res. Rep. 257, U.S. Army Cold Reg. Res. and Eng. Lab., Hanover, New Hampshire, 1968.

Barnes, J. F., P. J. Blewett, R. G. McQueen, K. A. Meyer, and D. Venable, Taylor instability in solids, J. Appl. Phys., 45, 727-732, 1974.

Bjork, R. L., Analysis of the formation of Meteor Crater, Arizona: A preliminary report, J. Geophys. Res., 66, 3379-3388, 1961.

Brin, D. G., Three models of dust layers on cometary nuclei, Astrophys. J., 237, 265-279, 1980.

Bryan, J. B., D. E. Burton, M. E. Cunningham, and L. A. Lettis, Jr., A two-dimensional computer simulation of hypervelocity impact cratering: Some preliminary results for Meteor Crater, Arizona, Proc. Lunar Sci. Conf., 9th, 3931-3964, 1978.

Campbell, D. B., B. A. Burns, and V. Boriakoff, Venus: Further evidence of impact cratering and tectonic activity from radar observations, Science, 204, 1424-1427, 1979.

Drucker, D. C., Taylor instability of the surface of an elastic-plastic plate, Mech. Today, 5, 37-47, 1980.

Gaffney, E. S., and T. J. Ahrens, Identification of ice VI on the Hugoniot of ice $I_{h}$, Geophys. Res. Lett., 7, 407-409, 1980.

Glass, B. P., Silicate spherules from Tunguska impact area: Electron microprobe analysis, Science, 164, 547-549, 1969.

Hageman, L. J., and J. M. Walsh, Help, a multimaterial eulerian program for compressible fluid and elastic-plastic flows in two space dimensions and time, Rep. 3SR-350, vol. 1, Systems, Science and Software, La Jolla, Calif., 1970.

Henderson-Sellers, A., A. Benlow, and A. J. Meadows, The early atmospheres of the terrestrial planets, Q. J. R. Astron. Soc., 21, 74-81, 1980.

Krinov, E. L., Giant Meteorites, 397 pp., Pergamon, New York, 1966.

Lamb, H., Hydrodynamics, 6th ed., 738 pp., Dover, New York, 1932.

Larsen, D. G., G. D. Bearson, and J. R. Taylor, Shock wave studies of ice and two frozen soils, in Permafrost, 2nd International Conference, North American Contribution, pp. 318-325, National Academy of Science, Washington, D.C., 1973.

Liu, V. C., A test of the comet hypothesis of the Tunguska Meteor Fall: Nature of the meteor 'thermal' explosion paradox, Geophys. Res. Lett., 5, 309-311, 1978.

Maxwell, D. E., Simple $\mathbf{Z}$ model of cratering, ejection, and the overturned flap, in Impact and Explosion Cratering, edited by D. J. Roddy, R. O. Pepin, and R. B. Merrill, pp. 1003-1008, Pergamon, New York, 1977.

McCaulley, J. F., M. H. Carr, J. A. Cutts, W. K. Hartmann, H. Masursky, D. J. Milton, R. P. Sharp, and D. E. Wilhelms, Prelim- 
inary Mariner 9 report on the geology of Mars, Icarus, 17, 289-327, 1972.

Melosh, H. J., and W. B. McKinnon, The mechanics of ringed basin formation, Geophys. Res. Lett., 5, 985-988, 1978.

Menikoff, R., R. C. Mjolsness, D. H. Sharp, and C. Zemach, Unstable normal mode for Rayleigh-Taylor instability in viscous fluids, Phys. Fluids, 20, 2000-2004, 1977.

Menikoff, R., R. J. Mjolsness, D. H. Sharp, C. Zemach, and B. J. Doyle, Initial value problem for Rayleigh-Taylor instability of viscous fluids, Phys. Fluids, 21, 1674-1687, 1978.

Mitchell, A. C., and W. J. Nellis, Water Hugoniot measurements in the range 30 to $220 \mathrm{GPa}$, High Pressure Science and Technology, vol. 1, edited by K. D. Timmerhaus and M. S. Barber, pp. 428-434, Plenum, New York, 1979.

Murray, B. C., M. J. S. Belton, G. E. Danielson, M. E. Davies, B. Hapke, B. T. O'Leary, R. G. Strom, V. E. Suomi, and N. J. Trask, Mariner 10 pictures of Mercury: First results, Science, 184, $459,1974$.

O'Keefe, J. D. and T. J. Ahrens, Shock effects from a large impact on the moon, Proc. Lunar Planet. Sci. Conf., 6th, 2831-2844, 1975.

O'Keefe, J. D., and T. J. Ahrens, Impact-induced energy partitioning melting and vaporization on terrestrial planets, Proc. Lunar Sci. Conf., 8th 3357-3374, 1977a.

O'Keefe, J. D., and T. J. Ahrens, Meteorite impact ejecta: Dependence of mass and energy lost on planetary escape velocity, Science, 198, 1249-1251, $1977 b$.

O'Keefe, J. D., and T. J. Ahrens, Impact flows and crater scaling on the moon, Phys. Earth Planet. Inter., 16, 341-351, 1978.

O'Keefe, J. D., and T. J. Ahrens, The effect of gravity on impact crater excavation time and maximum depth; comparison with experiment (abstract), Lunar Planet. Sci., X, 934-936, 1979.

O'Keefe, J. D., and T. J. Ahrens, Impact cratering: The effect of crustal strength and planetary gravity, Rev. Geophys. Space Phys., $19,1-12,1981$.

Palme, H., E. Gobel, and R. A. F. Grieve, The distribution of volatile and siderophile elements in the impact melt of East Clearwater (Quebec), Proc. Lunar Planet. Sci. Conf.. 10, 2465-2492, 1979.

Passey, Q. R., and H. J. Melosh, Effects of atmospheric breakup on crater field formation, Icarus, 42, 211-233, 1980.

Petrov, G. I., and V. P. Stulov, Motion of large bodies in the atmospheres of planets, Cosmic Res., 13, 525-531, 1976.

Pettengill, G. H., P. G. Ford, W. E. Brown, W. M. Kaula, H. Masursky, E. Eliason and G. E. McGill, Venus: Preliminary topographic and surface imaging results from the Pioneer orbiter, Science, 205, 91-93, 1979.

Quaide, W. L., and V. R. Oberbeck, Thickness determination of the lunar surface layer from lunar impact craters, J. Geophys. Res., 73, 5247-5270, 1968.

Ramberg, H., Gravity, Deformation and the Earth's Crust, 214 pp., Academic, New York, 1967.

Ringwood, A. E., Origin of the Earth and the Moon, 295 pp., Springer-Verlag, New York, 1979.

Robie, R. A., B. S. Hemingway, and J. R. Fisher, Thermodynamic properties of minerals and related substances at $298.15 \mathrm{~K}$ and 1 bar ( $10^{5}$ pascals) pressure and at higher temperatures, Bull. U.S. Geol. Surv., 1452, 1978.

Roddy, D. J., The Flynn Creek Crater, Tennessee, in Shock Metamorphism of Natural Materials, edited by B. M. French and N. M. Short, pp. 291-322, Mono, Baltimore, Maryland, 1968.

Roddy, D. J., Large-scale impact and explosion craters: Comparison of morphological and structural analogs, in Impact and Explosion Cratering, edited by D. J. Roddy, R. O. Pepin, and R. B. Merrill, pp. 185-246, Pergamon, New York, 1977.
Roddy, D. J., K. Kreyenhagen, S. Schuster, and D. Orphal, Theoretical and observational support for formation of flat-floored central uplift craters by low-density impacting bodies (abstract), Lunar Planet. Sci., XI, 943-945, 1980.

Schultz, P. H., D. L. Orphal, B. Miller, W. F. Borden, and S. A. Larson, Impact crater growth and ejecta characteristics: Results from computer simulations (abstract), Lunar Planet. Sci., XII 949-951, 1981.

Shoemaker, E. M., Astronomically observable crater-forming projectiles, in Impact and Explosion Cratering, edited by D. J. Roddy, R. O. Pepin, and R. B. Merrill, pp. 617-628, Pergamon, New York, 1977.

Shoemaker, E. M., M. H. Hait, G. A. Swann, D. L. Schleicher, G. G. Schaber, R. L. Sutton, and D. H. Dahlem, Origin of the lunar regolith of Tranquility Base, Proc. Apollo 11 Lunar Sci. Conf., 3 , 2399-2412, 1970.

Smith, B. A., L. A. Soderbloom, T. V. Johnson, A. P. Ingersoll, S. A. Collins, E. M. Shoemaker, G. E. Hunt, H. Masursky, M. H. Carr, M. E. Davies, A. F. Cook II, J. Boyce, G. E. Danielson, T. Owen, C. Sager, R. F. Beebe, J. Veverka, R. G. Strom, J. F. McCauley, D. Morrison, G. A. Briggs, and V. E. Suomi, The Jupiter system through the eyes of Voyager 1, Science, 204, 945-972, 1979.

Smith, J. V., Possible controls on the bulk composition of the earth: Implications for the origin of the earth and moon, Proc. Lunar Sci. Conf., 8th, 333-370, 1977.

Taylor, G., The instability of liquid surfaces when accelerated in a direction perpendicular to their planes, I, Proc. R. Soc. London. Ser. A, 201, 192-196, 1950.

Thomsen, J. M., M. G. Austin, and P. H. Schultz, The development of the ejecta plume in a laboratory-scale impact cratering event (abstract), Lunar Planet. Sci., XI, 1146-1148, 1980.

Tillotson, J. H., Metallic equations of state for hypervelocity impact, Gener. At. Rep. GA 3216, General Dynamics Corp., San Diego, Calif., 1962.

Ullrich, G. W., D. J. Roddy, and G. Simmons, Numerical simulations of a 20-ton TNT detonation on the earth's surface and implications concerning the mechanics of central uplift formation, in Impact and Explosion Cratering, edited by D. J. Roddy, R. $O$. Pepin, and R. B. Merrill, pp. 959-982, Pergamon, New York, 1977.

Veverka, J., and T. C. Duxbury, Viking observations of Phobos and Deimos: Preliminary results, J. Geophys. Res., 82, 4213-4233, 1977.

Veverka, J., P. Thomas, M. Davies, and D. Morrison, Amalthea, $J$. Geophys. Res., 86, 8675-8692, 1981.

Wetherill, G. W., Where do the meteorites come from? A reevaluation of the earth-crossing Apollo objects as sources of stone meteorites, Geochim. Cosmochim. Acta, 40, 1297-1317, 1976.

Wetherill, G. W., The nature of the present interplanetary craterforming projectiles, in Impact and Explosion Cratering, edited by D. J. Roddy, R. O. Pepin, and R. B. Merrill, pp. 613-616, Pergamon, New York, 1977.

Whipple, F. L., The constitution of cometary nuclei, in Comets, Asteroids, Meteorites: Interrelations, Evolution and Origins, edited by A. H. Delsemme, pp. 25-35, University of Toledo Press, Toledo, Ohio, 1977.
(Received October 25, 1980; revised June 2, 1981; accepted July 31, 1981.) 